\title{
MOLDAGEM EM PRÓTESE TOTAL PARA MUCOSA FLÁCIDA
}

Felipe Ambrosio TEODORO, Erika Ferreira de PAULA, Eduardo CARRILHO, José Stechman NETO, Paulo Augusto Pires MILANI

A moldagem do rebordo é uma fase crítica na confecção de uma prótese total principalmente se a mucosa for flácida. Esta pode sofrer alteração de posição pela ação do material utilizado e isto pode comprometer fidelidade do modelo que terá sua topografia original alterada, resultando em prótese mal adaptada (FILHO, 2004). Paciente de 81 anos, gênero feminino, melanoderma, compareceu à clinica com a necessidade de confecção de prótese total superior e inferior, e após exame clinico constatou-se mucosa flácida na região anterior com deslocamento ao contato digital. Optou-se então por uma moldagem sem compressão. Confeccionou-se uma moldeira modificada, através de alívios e aberturas, primeiramente, moldou-se à região posterior, por esta não apresentar deformação. Em seguida injetou-se o material para moldagem em um sistema de orifícios para entrada e escoamento do poliéter na região do tecido que apresentava mobilidade. O objetivo dessa técnica é a obtenção de uma copia fiel do rebordo sem compressão evitando deslocamentos indevidos de tecido fibroso, e má-adaptação da prótese total. 